\title{
Características das transações do etanol carburante entre distribuidoras e revendedores
}

\section{Characteristics of brazilian sugarcane ethanol fuel transactions between distributors and retail stations}

\author{
Maíra Bacha Lopes ${ }^{1}$ \\ Andrea Lago da Silva ${ }^{1}$ \\ Luiz Fernando Paulillo'
}

\begin{abstract}
Resumo: O advento dos carros bicombustíveis no Brasil e a necessidade de uma fonte de energia alternativa ao petróleo acarretaram uma nova configuração no processo de distribuição do etanol. Essas mudanças trouxeram oportunidades para as empresas sucroalcooleiras do país e abriram diferentes horizontes para o desenvolvimento de canais de distribuição desse combustível nos âmbitos nacional e internacional. O presente trabalho tem o objetivo de mostrar como ocorrem as transações na relação entre as distribuidoras e os postos revendedores que compõem os canais de distribuição de etanol carburante. Na revisão de literatura, optou-se pelos conhecimentos da economia dos custos de transação, de modo a sustentar as variáveis utilizadas na análise (especificidades do negócio, frequências e riscos das transações). Na parte empírica, foram elaborados estudos de casos múltiplos, a partir de entrevistas pessoais realizadas em nove empresas (distribuidoras e postos revendedores) do Estado de São Paulo. Os resultados mostram que as especificidades mais importantes do negócio de uma distribuidora de combustíveis estão ligadas às especificidades físicas, de local e de marca. As principais especificidades relacionadas aos postos revendedores são iguais às identificadas nas distribuidoras, apresentando diferenças somente nas especificidades locacionais e físicas. Na relação entre esses agentes, destacam-se as formas de governança de mercado spot e contratual.
\end{abstract}

Palavras-chave: Etanol carburante. Custos de transação. Governança. Distribuidoras. Postos revendedores.

\begin{abstract}
The development of flexible-fuel vehicles in Brazil and the need for an alternative energy source to oil (Petroleum) has lead to a reconfiguration of the ethanol distribution process. These changes have brought new opportunities to the Brazilian sugarcane ethanol fuel industry and new directions to the development of ethanol marketing channels in the national and international levels. The present study aims to show how transactions between ethanol distributors and retail stations occur. The research was conducted as a multiple case study by collecting data through in-person interviews in nine companies which are representative members of the ethanol marketing channels (distributors and retail stations) in the state of Sao Paulo, Brazil. The data analysis was performed using the cost transactions economics theory to evaluate the variables used in the analysis (business specificities, frequency, and transaction risks). The results indicate that the most important specificities of the fuel distributors business are related to physical specificities such as locational and brand assets. With regard to the retail stations, the major specificities identified were the same, except for the physical and locational assets. Governance forms based on contractual and spot market stand out in the relationship between the two agents investigated
\end{abstract}

Keywords: Brazilian sugarcane ethanol fuel. Transaction costs. Governance. Distributors. Retail stations.

\section{Introdução}

O advento dos carros bicombustíveis em 2003 e a necessidade de uma fonte de energia alternativa ao petróleo levaram ao aumento da participação do etanol no mercado interno. De acordo com dados do Anuário Estatístico da Agência Nacional do Petróleo - ANP (2008), as vendas das distribuidoras de álcool etílico hidratado totalizaram 9,4 milhões de metros cúbicos em 2007, um volume 51,4\% superior ao de 2006. Todas as regiões do Brasil apresentaram crescimento em suas vendas nesse ano: a Região Sudeste, responsável por $70,2 \%$ do mercado nacional, teve seu volume de vendas acrescido em 50,1\%; apenas as vendas da Região Sul tiveram crescimento percentual inferior ao da

\footnotetext{
${ }^{1}$ Departamento de Engenharia de Produção, Grupo de Estudos e Pesquisas Agroindustriais, Universidade Federal de São Carlos UFSCar, Rod. Washington Luís, Km 235, CP 676, CEP 13560-970, São Carlos - SP, E-mails: maira_lopes@yahoo.com; deialago@ufscar.br; dlfp@ufscar.br
} 
Região Sudeste, porém ainda assim muito expressivo $(33,4 \%)$. As regiões Norte, Nordeste e Centro-Oeste tiveram crescimento extremamente expressivo em suas vendas de álcool etílico hidratado: 96,7\%, 70,1\% e $74,6 \%$, respectivamente. Essas mudanças trouxeram oportunidades para as indústrias sucroalcooleiras e abriram diferentes horizontes para o desenvolvimento de canais de distribuição desse combustível, seja no âmbito nacional, seja no internacional.

Em um mercado em que cada vez mais o etanol é a alternativa não só à gasolina, como também ao gás natural e ao diesel, existe a necessidade de se ter muito bem definidos os mecanismos de comercialização desse produto. Para tanto, percebe-se a importância do entendimento de como se estruturam e se comportam os membros dos canais de distribuição do setor.

No entanto, apesar de muito se discutir a respeito da expansão do etanol no mercado interno, ainda pouca atenção acadêmica foi dada à compreensão de como se estruturam e se comportam os membros desses canais. O estudo da distribuição desse combustível tem grande importância, pois está relacionada à capacidade de abastecimento do mercado. O entendimento de sua dinâmica contribui para o equacionamento eficiente do fluxo e da logística de abastecimento, fazendo-se necessário para suportar a proposição de políticas públicas, ou mesmo para dar base à tomada de decisões estratégicas por agentes do setor, o que impacta diretamente no crescimento dos mercados interno e externo do etanol brasileiro (DOLNIKOFF, 2008).

Uma tendência recente na literatura de marketing é um aumento do interesse em estudar problemas vinculados à gestão de relacionamento (DWYER; SCHURR; OH, 1987; ANDERSON; NARUS, 1990; LEE; CAVUSGIL, 2006; KIM, 2007; LUI; WONG; LIU, 2009). Alguns desses autores têm examinado questões de relacionamento utilizando a "economia das organizações" como paradigma. Em particular, a economia do custo de transação tem sido extensivamente usada (ANDERSON, 1985; HEIDE; JOHN, 1988; KLEIN; FRAZIER; ROTH, 1990; RINDFLEISCH; HEIDE, 1997; POPPO; ZENGER, 2002; JAP; ANDERSON, 2003; AULAKH; GENCTURK, 2008).

Nesse contexto, o presente artigo tem como objetivo investigar quais os atributos relevantes das transações entre as distribuidoras e os postos revendedores que compõem os canais de distribuição de etanol carburante no Brasil e quais as estruturas de governança predominantes. Para isso, o artigo está organizado da seguinte forma: após a introdução, é detalhado o modo de realização da coleta e da análise dos dados; em seguida, é apresentado o referencial teórico utilizado como suporte para as investigações; na sequência, é apresentada uma seção sobre o panorama atual da cadeia de etanol no Brasil e seu mercado interno. Por fim, são apresentados e discutidos os resultados, finalizando-se com as conclusões e sugestões para trabalhos futuros.

\section{Procedimentos metodológicos}

A pesquisa se caracteriza por utilizar a abordagem qualitativa e por ser do tipo exploratória, já que existem poucos trabalhos que analisam as relações entre os membros dos canais de distribuição de etanol carburante (YIN, 2005).

Dentro desse contexto de pesquisa qualitativa e exploratória, a pesquisa utilizou o método de estudo de casos múltiplos. Conforme analisado por Boyd e Westfall (1987), esse método é adequado, pois pode ser útil na descoberta de três fatores: a) fatores que são comuns a todos os casos no grupo escolhido; b) fatores que não são comuns a todos, mas apenas a alguns subgrupos, e c) fatores que são únicos num caso específico.

Nesta pesquisa, a amostra de caráter não probabilístico foi escolhida por meio de uma amostragem por conveniência. Segundo Selltiz et al. (1974), essa técnica é a mais apropriada, pois permite a seleção de componentes da amostra de acordo com as características necessárias para a obtenção de casos considerados típicos nesta população. Dessa forma, foram selecionados os membros desses canais levando em conta os diferentes fatores (Quadro 1) que os caracterizam:

- 1 distribuidora emergente;

- 3 distribuidoras vinculadas ao Sindicom (Sindicato Nacional das Empresas de Combustíveis e Lubrificantes);

- 2 postos bandeira branca; e

- 3 postos bandeirados.

Destaca-se que também foram coletadas informações nas associações de classes, como o Sindicato Nacional das Empresas de Combustíveis e Lubrificantes - SINDICOM e o Sindicato do Comércio Varejista de Derivados de Petróleo do Estado de São Paulo - SINCOPETRO.

O universo de análise restringiu-se ao Estado de São Paulo, devido à sua importância na produção do combustível. O Estado de São Paulo é o maior produtor de etanol do Brasil (60\% da produção nacional) e possui o maior mercado consumidor do produto (responsável, respectivamente, por $59 \%$ e $30 \%$ das vendas de etanol hidratado e anidro) (AGÊNCIA..., 2008), além das melhores estruturas logísticas e instituições de pesquisas, que também (ou apenas) desenvolvem estudos sobre o setor sucroenegético, como o CTC, DEP-UFSCar, ESALQ-USP, FEARP-USP, CEPEA, entre outras. 
Quadro 1. Características dos membros analisados.

\begin{tabular}{|ll|}
\hline Distribuidoras & - As distribuidoras emergentes, que surgiram no mercado após a desregulamentação do setor, \\
& são companhias com menor participação no mercado, com marcas menos conhecidas, menor \\
& volume de venda, que nem sempre possuem rede de postos e geralmente trabalham apenas com \\
& a distribuição de etanol, atuando mais regionalmente. \\
& - As distribuidoras do Sindicom são as maiores, com marcas mais conhecidas, que possuem \\
& redes de postos com suas bandeiras e com maior participação no mercado de distribuição de \\
& combustíveis. De acordo com dados do Sindicom (SINDICATO..., 2009), as distribuidoras \\
& que fazem parte dessa associação, são: AirBP, Ale, Castrol, Chevron (Texaco no Brasil), Esso, \\
& Ipiranga, BR Distribuidora, Petronas Lubrificantes, Repsol e Shell. Vale frisar que atualmente \\
& existem distribuidoras emergentes, como a Ale, que também fazem parte do Sindicom. \\
Postos & - Posto bandeirado: quando opta por exibir a marca comercial de um distribuidor, o posto deve \\
revendedores & vender somente combustíveis fornecidos pelo distribuidor detentor da marca comercial exibida \\
& aos consumidores; \\
& - Posto bandeira branca: quando opta por não exibir marca comercial de nenhuma distribuidora, \\
& o posto deve identificar, de forma destacada e de fácil visualização pelos consumidores, em \\
& cada bomba abastecedora, o distribuidor fornecedor do respectivo combustível. \\
& -Atualmente, a Lei n. $9478 / 1997$ e a Portaria ANP n. 116/2000 vedam às distribuidoras o \\
& exercício da atividade de varejista de combustíveis, mas não o direito à propriedade de postos \\
& de combustíveis. \\
& - De acordo com a Resolução da ANP n. 4, de 08/02/2006, as distribuidoras podem operar no \\
& varejo no caso dos postos-escola.
\end{tabular}

Fonte: elaborado pelos autores.

Os dados foram coletados durante o segundo semestre de 2008, de julho a dezembro, por meio de entrevistas pessoais com os gerentes responsáveis pela comercialização do etanol das nove empresas estudadas. As entrevistas duraram em média 1h30, foram gravadas e então transcritas com o intuito de identificar semelhanças e diferenças entre os casos estudados. As entrevistas desta pesquisa caracterizam-se por ser do tipo semiestruturada. Segundo Triviños (1992), a entrevista semiestruturada parte de certos questionamentos básicos, apoiados na teoria, contudo não é estruturada estatisticamente, o que permite flexibilidade em sua condução.

Para análise dos dados, a estratégia analítica utilizada foi do tipo descritiva e optou-se pela técnica de síntese de casos cruzados (YIN, 2005). Para essa análise, a transcrição obtida em cada caso foi estudada em profundidade. Para facilitar o encontro de respostas padrões e a frequência com a qual essas respostas apareceram em um determinado contexto, as informações obtidas em cada caso foram fragmentadas em categorias de acordo com os tópicos principais investigados na pesquisa (Figura 1). Esses tópicos foram definidos em função do conhecimento acerca da ECT, sendo utilizados como aporte teórico no trabalho.

Após o detalhamento sobre como foram feitas a escolha das unidades de análise, a coleta e a análise dos dados, a Figura 1 sintetiza como foram elaborados os roteiros de entrevista de acordo com os objetivos, as unidades de análises e os temas (tópicos) investigados na pesquisa.

\section{Referencial teórico}

\subsection{Economia dos Custos de Transação - ECT}

Segundo Zylberzstajn (1995), o objetivo fundamental da ECT é analisar os custos de transação como o elemento indutor dos modos alternativos de estruturas de governança escolhidos pela empresa ao mercado tradicional (spot), dentro de um arcabouço analítico institucional. Assim, a unidade de análise fundamental passa a ser a transação, operação em que são negociados direitos de propriedade. Uma transação frequentemente sujeita as partes envolvidas ao risco de que elementos acordados entre elas não se efetivem. No entanto, as partes não observam esses riscos passivamente, mas criam mecanismos e estruturas de governança que têm por objetivo último a redução de tais riscos e suas consequências. Além dos riscos inerentes, especificidades variadas do negócio e aumentos das frequências dos relacionamentos econômicos tendem a estimular os custos de negociação.

Os custos de transação são, portanto, os custos de conduzir o sistema econômico, tendo como unidade econômica básica a transação (WILLIAMSON, 1996). Ou seja, trata-se de uma teoria que permite analisar as organizações e seu relacionamento com o mercado e as instituições (regras, normas, convenções, rotinas, etc.), a partir das características dos negócios, dos oportunismos empreendidos pelos negociadores e da incerteza inerente aos mercados imperfeitos atuais. 


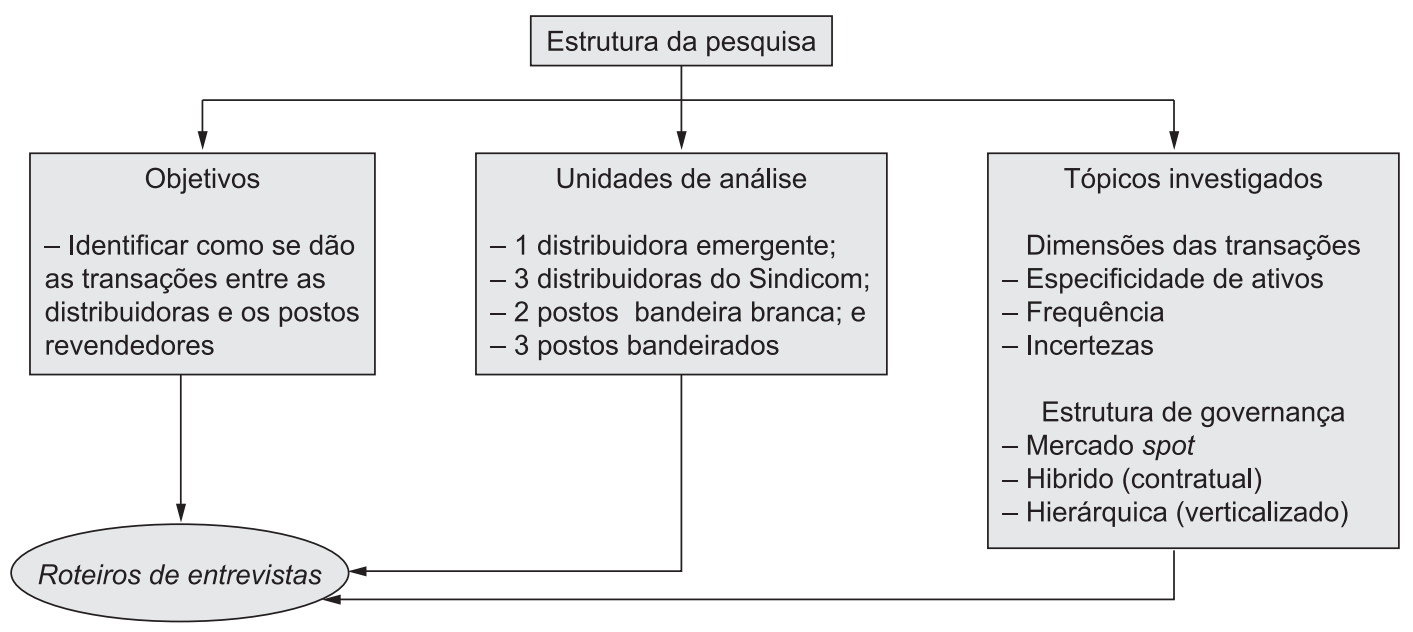

Figura 1. Estrutura da pesquisa. Fonte: Elaborado pelos autores.

São três os atributos de transação priorizados por Williamson (1975) para mostrar a definição da coordenação do negócio pela firma: frequência, incerteza e especificidades do ativo.

\section{A) Frequência}

Indica a quantidade de vezes que determinadas transações ocorrem entre os agentes, sendo a medida de recorrência da transação. A relação contratual entre as duas partes é diretamente influenciada por esse atributo, uma vez que surgem formas contratuais alternativas a partir de diferentes frequências de transação (ZYLBERSZTAJN, 2000).

Williamson (1985) classifica a frequência em recorrente ou ocasional. Algumas se resolvem em um único ponto no tempo (ocasional), enquanto outras são recorrentes. O custo de transação relativo a uma única transação não é suficientemente grande para que se monte uma estrutura de controle dessa transação, de tal modo que essas operações de compra e venda são normalmente realizadas através do mercado spot. North (1990) ressalta que o mercado spot também pode ser utilizado em transações com alta frequência quando o efeito reputação é importante.

Em transações recorrentes, as partes são estimuladas a desenvolver reputação, limitando seu interesse em agir de modo oportunista para obter ganhos de curto prazo (RINDFLEISCH; HEIDE, 1997). Na medida em que se aumenta a frequência de uma dada transação, possibilita-se a construção de reputação entre as partes, com impacto na redução dos custos de transação. A repetição de uma transação possibilita que as partes adquiram conhecimento umas das outras (o que reduz a incerteza); que se construa uma reputação em torno de uma marca (o que cria um ativo específico), e, ainda mais importante, que se crie, em alguns casos, um compromisso confiável entre as partes em torno do objetivo comum de continuidade da relação (FARINA; AZEVEDO; SAES, 1997).

\section{B) Incerteza}

Cabe aqui o conceito de Knight (1921 apud ZYLBERSZTAJN, 2000), que associa incerteza a efeitos não previsíveis, não passíveis de terem uma função de probabilidade conhecida a eles associada. Essa impossibilidade de previsão de choques - que possam alterar as características dos resultados da transação - não permite que os agentes que dela participam desenhem cláusulas contratuais que associem a distribuição dos resultados aos impactos externos, uma vez que estes não são conhecidos exante.

Para North (1990), incerteza corresponde efetivamente ao desconhecimento dos possíveis eventos futuros. Nesse sentido, incerteza implica a impossibilidade de definição de uma distribuição de probabilidades.

Tanto no tratamento da incerteza enquanto desconhecimento quanto naquele sentido que enfatiza a assimetria informacional, o papel que a dimensão "incerteza" representa é o de revelar os limites da racionalidade limitada e, portanto, evidenciar a incompletude dos contratos. Diante disso, trata-se de uma dimensão profundamente conectada ao pressuposto comportamental da racionalidade limitada (FARINA; AZEVEDO; SAES, 1997). Ou seja, as transações com maior incerteza deverão ter mais adaptações futuras em contratos e demandam estruturas de controle mais complexas, com custo muito elevado, interferindo na forma como as transações ocorrerão (NEVES, 1999).

Segundo Farina, Azevedo e Saes (1997), a incerteza tem como principal papel a ampliação das lacunas que um contrato não pode cobrir. No ambiente de incerteza, os agentes não conseguem prever os 
acontecimentos futuros e, assim, o espaço para renegociação é maior. Sendo maior esse espaço, maiores serão as possibilidades de perdas derivadas do comportamento oportunista das partes.

\section{C) Especificidade dos ativos}

Esta característica das transações é definida por Williamson (1985) como a perda de valor dos ativos envolvidos em determinada transação, no caso de esta não se concretizar ou no caso do rompimento contratual. Alta especificidade de ativos significa que uma ou ambas as partes envolvidas na transação perderão, caso esta não se concretize, por não encontrarem uso alternativo que mantenha o valor do ativo desenvolvido para determinada transação. A partir desse conceito, ativos específicos são aqueles que não podem ser alocados de forma alternativa, a não ser com perda de valor (PETERSON; WYSOCKI; HARSH, 2001).

Segundo Williamson (1996), as especificidades dos ativos (negócios) podem ser classificadas em pelos menos seis categorias:

- de lugar, que dizem respeito à economia em transporte e estocagem entre unidades produtivas;

- físicas, que se referem à necessidade de determinados equipamentos ou componentes para viabilizar o processo produtivo;

- humanas, relacionadas ao capital humano;

- dedicadas (de exclusividade de uma contratação), que são investimentos cujo retorno depende da transação com um agente em particular e para o qual foram realizados investimentos de marca e tempo;

- temporais, cuja principal característica é o tempo que diferencia um negócio dos demais, limitando seu uso; e

- de marca, relacionadas à reputação que o nome da empresa ou do produto tem no mercado.

\subsection{Estruturas de governança}

Da mesma forma que uma transação difere com base em seus atributos - especificidades do negócio, frequência e incerteza - é também necessário dimensionar as estruturas de governança. Segundo Williamson (1996), estas diferem em seus custos e competências, principalmente, ao economizar em custos de transação. A diferença-chave entre as formas de governança (mercado, formas híbridas e hierarquia) é o modelo contratual, porém diferenças em adaptabilidade e no uso de instrumentos de incentivo e/ou controle são variáveis a ser consideradas. Em síntese, à medida que se caminha do mercado para a estrutura hierárquica de coordenação, perde-se em incentivo e pode-se ganhar em controle. Da mesma forma, o investimento em especificidades representa maior vulnerabilidade às ações oportunistas, demandando maior controle, e assim a forma hierárquica se apresenta como a mais eficaz forma de governança caso o custo de transação seja muito elevado (AZEVEDO, 1996).

Para a identificação da mais efetiva forma de governança, as características básicas das transações especificidades, riscos antes e após a negociação, e frequência - devem ser avaliadas com base nos pressupostos comportamentais - oportunismo e racionalidade limitada. A Figura 2 traz a forma com a qual essas variáveis se inter-relacionam de modo a induzir formas de governança que viabilizem a redução de custos de transação. Dessa maneira, as características básicas da transação determinam um formato contratual que, sob um determinado ambiente institucional e comportamento dos agentes, induz à estrutura de governança mais apropriada.

O mercado é tido como o mais eficiente modo de governança quando o preço é o melhor instrumento de coordenação. Essa realidade é válida para commodities, em que a frequência de relação é baixa, investimentos específicos não são realizados e os riscos da transação são baixos. Em relações de mercado, a intensidade de

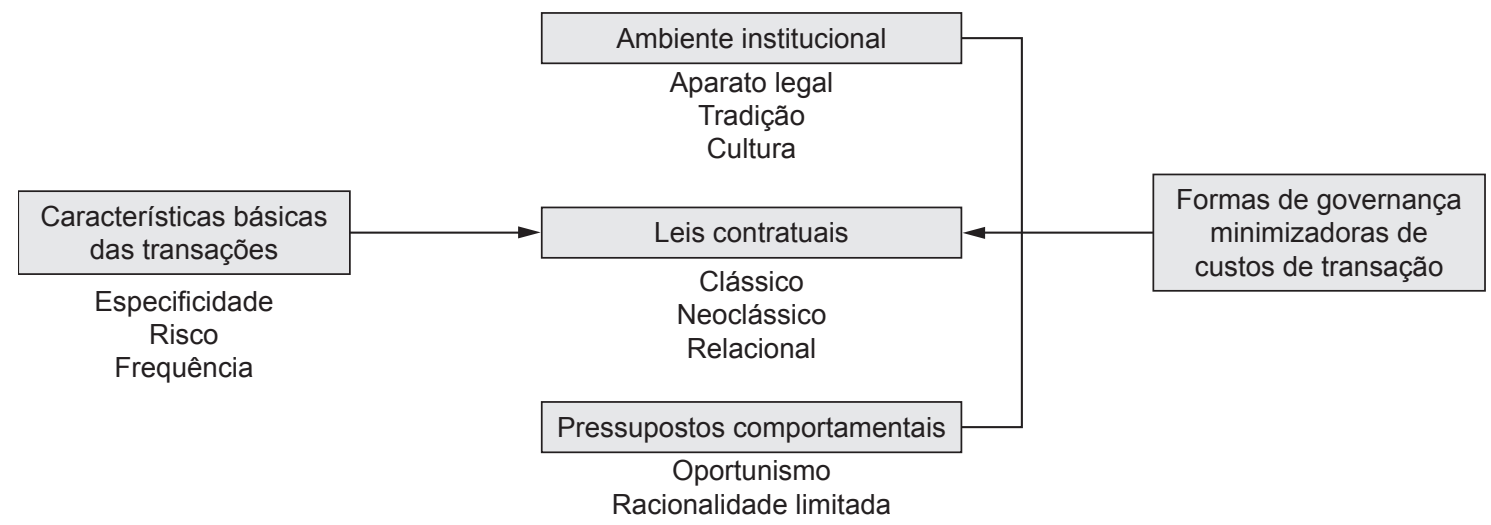

Figura 2. Esquema da indução das formas de governança. Fonte: Zylbersztajn (1995, p. 23). 
coordenação é baixa e a "mão invisível" - o conceito de mercado de Adam Smith - determina o preço e os padrões de desempenho. O único controle exercido pelas partes é o envolvimento na descoberta do preço e a decisão em participar ou não da negociação. Dessa forma, o controle é exercido inteiramente ex ante à transação (PETERSON; WYSOCKI; HARSH, 2001).

No extremo oposto desta escala de modelos de governança, tem-se a hierarquização das relações, situação em que a realização de investimentos específicos, atrelados ao alto grau de incerteza, resulta em modelos de coordenação vertical. A intensidade de controle, necessária para alinhar e manter os interesses mútuos, é significativamente mais complexa do que aquela apresentada pela estrutura de mercado spot. Neste modelo, os controles ex post, responsáveis pelo monitoramento das relações e pelo desempenho da transação, são de grande relevância para os mecanismos de controle estabelecidos (PETERSON; WYSOCKI; HARSH, 2001).

No caso do modo de governança contratual, de acordo com Menard (2001; 2004), um contrato pode ter diferentes formas e conteúdos, e sua elaboração deverá representar um formato híbrido de coordenação entre os extremos de integração vertical e mercado spot. Segundo o autor, o terreno torna-se menos preciso quando se move de mercado para hierarquia. Os formatos de contratos colocados por ele são de subcontratação, com uma característica de contratos duradouros que envolvem os mesmos parceiros; networks de empresas como sendo contratos recorrentes entre unidades autônomas tanto para suprimento quanto para distribuição; contratos de franquias, empresas que alugam suas marcas, mas que enfrentam problemas de coordenação e manutenção em função disso; marcas coletivas, por exemplo, associações de varejistas; parceria, mas neste caso os vínculos são menos formalizados, e, por fim, alianças, por exemplo, para transferência de tecnologia.

\section{Panorama atual da cadeia de etanol no Brasil e seu mercado interno}

O Brasil é o maior produtor mundial de etanol, utilizando a cana-de-açúcar como matéria-prima. De acordo com dados da União da Indústria de Cana-de-Açúcar - UNICA (2008), na safra 2007/08, o volume de cana esmagada foi de 493,38 milhões de toneladas. Nos últimos anos, o País apresentou crescimento na produção de cana, avançando em áreas de outras culturas importantes (laranja, soja, milho) e, principalmente, sobre as áreas de pecuária extensiva.

A região Centro-Sul foi responsável por $87,4 \%$ da produção de cana-de-açúcar na safra de 2007/08
(UNIÃO..., 2008). Essa região, que tem São Paulo como maior estado produtor, é a que apresenta as maiores produtividades agrícola e industrial, e os menores custos de produção e de logística, pois está mais próxima do mercado consumidor, dos centros de pesquisa e da indústria de máquinas e equipamentos para o setor. Já as usinas e destilarias da região Norte-Nordeste, com os 12,6\% restantes da produção de cana do país, encontram maiores dificuldades em adaptar-se às novas condições técnicas impostas pela desregulamentação do setor, apresentando custos de produção mais elevados (VIAN, 2002).

Nesse montante da produção de cana-de-açúcar, a Tabela 1 mostra como a produção de etanol está distribuída no Brasil, apresentando a evolução da produção do combustível entre 2002 e 2007 por grandes regiões. Observa-se que em 2007 a produção nacional de etanol carburante, tanto anidro como hidratado, deu continuidade à trajetória de crescimento iniciada em 2001, atingindo um volume aproximado de 22,6 milhões de metros cúbicos, que representou um aumento de $26,9 \%$ relativamente a 2006 . Como consequência, a taxa média anual de crescimento para o período 1998-2007 foi de 5,3\%. A região Sudeste, maior produtora nacional, com 15,8 milhões de metros cúbicos ( $70 \%$ da produção brasileira), apresentou taxa de crescimento de $26,5 \%$ em relação a 2006, e o Estado de São Paulo, principal produtor nacional, incrementou sua produção em $24 \%$ no período. Foram produzidos neste estado 13,6 milhões de metros cúbicos, correspondentes a $60,2 \%$ da produção nacional e a $86,1 \%$ da produção da região Sudeste (AGÊNCIA..., 2008).

Em 2007, a região Norte teve forte queda em sua produção, com redução de $37,2 \%$ em relação a 2006. No Sudeste, houve aumento de produção de $26,5 \%$ nesse período, dando continuidade aos seguidos incrementos registrados desde 2001. A região Nordeste retomou o crescimento da produção $(20,9 \%)$ em relação a 2006, ano em que esta havia caído em relação ao ano anterior. Na região Centro-Oeste, foi registrada taxa de crescimento de $24,6 \%$, com destaque para os incrementos verificados nos estados do Mato Grosso do Sul $(35,5 \%)$ e de Goiás $(33,5 \%)$ (AGÊNCIA..., 2008).

O mercado nacional de etanol é composto pelas vendas de álcool etílico anidro (que contém $0,7 \%$ de água) e de álcool etílico hidratado (que contém de $6,2 \%$ a 7,4\% de água). O consumo de álcool anidro está relacionado ao consumo da gasolina $\mathrm{C}$, visto que é misturado na proporção de 25\% na gasolina A para a constituição daquela. $\mathrm{O}$ álcool hidratado, por sua vez, é consumido pelos carros movidos puramente a álcool ou pelos carros bicombustíveis. 
Tabela 1. Evolução da produção de álcool etílico entre 2002 e 2007 por grandes regiões.

\begin{tabular}{lrrrrrrr}
\hline \multicolumn{7}{c}{ Produção de álcool etílico anidro e hidratado $\left(\mathbf{m i l ~ m}^{\mathbf{3}}\right)$} \\
\hline Grandes regiões & \multicolumn{1}{c}{$\mathbf{2 0 0 2}$} & \multicolumn{1}{c}{$\mathbf{2 0 0 3}$} & $\mathbf{2 0 0 4}$ & $\mathbf{2 0 0 5}$ & \multicolumn{1}{c}{$\mathbf{2 0 0 6}$} & \multicolumn{1}{c}{$\mathbf{2 0 0 7}$} & $\mathbf{0 7 / 0 6} \%$ \\
\hline Total & $12.588,62$ & $14.469,95$ & $14.647,25$ & $16.039,89$ & $17.764,26$ & $22.556,90$ & \multicolumn{1}{c}{26,98} \\
Norte & 30,32 & 39,39 & 47,53 & 47,51 & 75,88 & 47,66 & $-37,20$ \\
Nordeste & $1.518,28$ & $1.505,23$ & $1.675,49$ & $1.675,49$ & $1.572,56$ & $1.901,72$ & 20,93 \\
Sudeste & $7.753,90$ & $8.551,82$ & $9.948,40$ & $11.154,24$ & $12.478,67$ & $15.782,23$ & 26,47 \\
Sul & 974,95 & $1.209,45$ & $1.178,31$ & 995,67 & 1308,24 & $1.923,23$ & 47,01 \\
Centro-Oeste & $1.513,27$ & $1.929,26$ & $1.797,52$ & $2.146,91$ & $2.328,92$ & $2.902,06$ & 24,61 \\
\hline
\end{tabular}

Fonte: Elaborado pelos autores com base na tabela 4.1 do Anuário Estatístico da ANP (AGÊNCIA..., 2008).

Em 2003, com o advento dos veículos bicombustíveis e com a grande aceitação destes por parte dos consumidores, houve um reaquecimento no consumo de etanol hidratado no mercado interno, o que abre um novo horizonte para a expansão da agroindústria da cana no Brasil. Rodrigues e Rodrigues (2008) argumentam que certamente o carro flex é um dos maiores patrimônios que o Brasil desenvolveu na rota dos combustíveis renováveis, pois o crescimento da frota flex, aliado à competitividade do etanol em grande parte do território nacional, foi responsável pelo renascimento do mercado de etanol carburante no país. Em março de 2003, quando surgiu o carro flex, as vendas de álcool etílico hidratado estavam em declínio e não totalizavam 250 milhões de litros mensais. Hoje, esse volume ultrapassa um bilhão de litros por mês, um aumento maior que $400 \%$ em cinco anos. Esse crescimento da demanda foi o motor propulsor da expansão da produção de etanol, que saltou de 14,8 bilhões de litros na safra 2003/04 para mais de 22 bilhões em 2007/08, devendo atingir 27 bilhões de litros na safra 2008/09.

Rodrigues e Rodrigues (2008) afirmam que o maior desafio do mercado interno de etanol é um planejamento estratégico da matriz brasileira de combustíveis, com uma diretriz clara sobre a participação do etanol nessa estrutura. De acordo com Pires e Schechtman (2008), no Brasil, as políticas de combustíveis veiculares sempre foram caracterizadas por movimentos ciclotímicos em resposta a situações conjunturais, sem uma visão de longo prazo. Foi assim no primeiro choque do petróleo, quando se incentivou a "dieselização" da frota de veículos na tentativa de conter a inflação. No segundo choque, visando a equilibrar o balanço de pagamentos, o governo lançou o Proálcool (Programa Nacional do Álcool) para substituir a gasolina por etanol e, a partir de 1986, no chamado contrachoque do petróleo, abandonou completamente o programa, retornando à gasolina. Mais recentemente, um excedente conjuntural provocado pela importação de gás natural da Bolívia levou a um incentivo desmedido do uso de gás natural veicular (GNV). Um ponto comum de todas essas políticas é a ausência de transparência na fixação do preço dos derivados de petróleo, muitas vezes sem sintonia com o mercado internacional.

\section{Resultados e discussão}

\subsection{Dimensões das transações: distribuidoras - revendedores}

Os ativos específicos mais importantes de uma distribuidora de combustíveis estão ligados às especificidades físicas, de local e de marca.

Para montar uma distribuidora, elevados investimentos são feitos em bases primárias e secundárias; no entanto, a prioridade é dada às bases primárias, já que estas recebem derivados de petróleo das refinarias diretamente por dutos. Existem três formas de operação das bases: as bases próprias, as bases que operam em sociedade (pools) e as bases alugadas de terceiros. As grandes distribuidoras geralmente já têm sua infraestrutura em bases consolidadas, fazendo com que investimentos menores sejam feitos em construções de novas bases. Normalmente, essas grandes distribuidoras arrendam um espaço de seu estoque para as distribuidoras emergentes, não sendo então necessário que estas construam bases próprias.

A maior parte dos custos das distribuidoras que possuem postos bandeirados está voltada para construção e reforma de seus postos franqueados. No entanto, essa dinâmica do mercado vem se alterando. No passado, as distribuidoras eram proprietárias de boa parte dos equipamentos que forneciam aos postos revendedores com os quais possuíam contrato de exclusividade. Atualmente, os revendedores preferem ser donos desses ativos, pois dessa forma dependem menos das distribuidoras. Além disso, é interessante para a distribuidora investir menos em equipamentos nos postos, pois assim ela pode elevar seus investimentos na divulgação da marca e no aumento de número de postos com sua bandeira, além de enfrentar menos problemas caso haja um rompimento contratual. Outro fator que vem se alterando é a diminuição dos investimentos das 
distribuidoras em postos próprios. Com o aumento dos custos para comprar terrenos e construir postos, além dos altos investimentos para adequar-se à legislação ambiental, possuir postos próprios passou a ser menos rentável.

O local dessas bases também tem muita importância, pois a logística é fundamental para o negócio, já que os valores pagos para o transporte dos combustíveis são altos. Desta forma, dependendo da distância do fornecedor até sua base ou da base até o consumidor final, a operação deixa de ser rentável ou eleva-se muito o preço final do produto.

A marca é um ativo importantíssimo para a distribuidora, já que este é um segmento em que existe muita desconfiança por parte do consumidor devido ao elevado número de casos de adulteração de combustíveis. Além disso, pelo fato de os combustíveis não apresentarem características de fácil percepção da qualidade (normalmente esta é notada após sua compra), a marca exerce um papel fundamental na garantia deste requisito. Como Machado (2002) argumenta, a reputação associada à determinada marca refere-se à confiança do consumidor na integridade do agente provedor do produto.

Em relação às especificidades dos postos revendedores, as relevantes são as locacionais, físicas e de marca. Pode-se dizer que as especificidades de marca se dão da mesma forma que para as distribuidoras. Mesmo nos casos de postos de bandeira branca, a imagem que o revendedor constrói de seu estabelecimento é importante para consolidar sua reputação e sua participação no mercado.

A especificidade locacional é uma das principais deste segmento. É importante que o revendedor conheça muito bem as potencialidades do local escolhido para montar seu posto de combustíveis. Os principais aspectos analisados são: tráfego, acesso e possibilidades de crescimento demográfico do comércio das imediações. Além disso, é importante considerar qual o público presente nesse local para definir quais serviços serão oferecidos e até mesmo optar por um posto bandeirado ou de bandeira branca. Por exemplo: há bairros que não comportam lojas de conveniência nos moldes tradicionais das grandes bandeiras, mas sim lojas menores, com outros tipos de produtos. Dependendo do perfil do consumidor, também se pode avaliar a necessidade ou não de uma bandeira conhecida para o negócio, já que em alguns casos a presença de uma marca conhecida encarece o produto e, para alguns consumidores, o principal atributo é o preço.

Quanto às especificidades físicas, nota-se que são altos os investimentos para se montar um posto de combustível; daí a necessidade de muitos revendedores estabelecerem contratos com uma distribuidora para auxiliá-los em seu empreendimento.

De acordo com o Art. $7^{\circ}$ da portaria da ANP n. 116 de 07/2000, a construção das instalações e a tancagem do posto revendedor deverão observar normas e regulamentos dos seguintes âmbitos:

- ANP;

- Associação Brasileira de Normas Técnicas - ABNT;

- Prefeitura Municipal;

- Corpo de Bombeiros;

- Proteção ao Meio Ambiente, de acordo com a legislação aplicável, e

- Departamento de Estradas de Rodagem, com circunscrição sobre a área de localização do posto revendedor.

Além dessas exigências, as Resoluções n. 273, de 29/11/2000 e n. 319, de 04/12/2002, ambas do Conselho Nacional do Meio Ambiente (Conama), que tratam do licenciamento prévio para localização, construção, instalação, modificação, ampliação e operação de postos revendedores, fizeram com que aumentassem ainda mais os investimentos em ativos físicos para construção de postos de combustíveis.

Em relação à frequência das transações entre as distribuidoras e os revendedores, a comercialização do etanol entre a distribuidora e um posto bandeirado é sempre recorrente, pois se dá por meio de contratos, como será mais bem explicado na seção seguinte - Estrutura de Governança. Já no caso da comercialização do combustível entre as distribuidoras e postos bandeiras brancas, mesmo que muitos desses postos prefiram manter negociações recorrentes com poucas distribuidoras de sua confiança, a frequência das transações em alguns casos é ocasional, já que não são firmados contratos de longo prazo entre as distribuidoras e esses agentes, o que lhes permite optar pela distribuidora que lhes ofereça as melhores vantagens no momento da aquisição do combustível.

No que diz respeito à incerteza, nota-se que, para a distribuidora, ela se manifesta de uma forma muito maior na relação da distribuidora com os postos revendedores do que na relação da distribuidora com as usinas. Pode-se analisar esse fato considerando as diferentes barreiras à entrada nos dois negócios. As poucas barreiras de entrada e as facilidades para deixar de ser uma distribuidora ou um revendedor fizeram com que esse mercado pós-desregulamentação se corrompesse, o que levou ao aumento da desconfiança entre esses agentes e também do consumidor final.

As principais práticas informais no mercado de etanol carburante são: "álcool molhado" 
(transformação do álcool anidro em hidratado por meio de adição de água); venda clandestina (venda direta das usinas às distribuidoras ou aos postos, sem recolhimento de tributos); adulteração (adição na gasolina de álcool ou "álcool molhado" acima da porcentagem permitida por lei) e contrabando (compra de álcool num estado com alíquota de ICMS menor e simulação de venda para estados com alíquota maior).

Algumas iniciativas vêm sendo tomadas pelo governo e pelas associações de classe (Sincopetro e Sindicom) para conter essas irregularidades, já que esses problemas do setor dificultam uma concorrência sadia entre seus agentes e gera um grande prejuízo ao estado devido às sonegações de impostos. Uma das iniciativas foi a obrigatoriedade da coloração do álcool anidro para acabar com a prática do "álcool molhado". Como o álcool hidratado é transparente, quando é acrescentado álcool anidro colorido no produto, sua cor é alterada, o que denuncia a adulteração. Além dessa iniciativa, devido à grande quantidade de distribuidoras que sonega impostos (PIS e COFINS), houve uma tentativa por parte do governo e das distribuidoras ligadas ao Sindicom de transferir os tributos do etanol para as usinas, assim como é feito na gasolina. Dessa forma, de acordo com a Medida Provisória (MP) 413, 100\% da cobrança dos tributos de PIS/Cofins se concentraria nas usinas. No entanto, os empresários do setor não aceitaram essa modificação, já que o problema que existe no segmento da distribuição seria transferido para as usinas e, com isso, as destilarias que atuam no mercado de maneira legal seriam prejudicadas com a atuação de usinas desonestas que, porventura, sonegassem esses impostos. Contudo, um acordo entre a União da Indústria da Cana-de-açúcar (UNICA) e o Sindicato Nacional das Distribuidoras de Combustíveis (Sindicom) estabeleceu o decreto da MP 425 que regulamentou o aumento na fatia do recolhimento dos tributos de $25 \%$ para $40 \%$ nas usinas e a redução de $75 \%$ para $60 \%$ nas distribuidoras.

Como pode ser observado, o mercado de distribuição e revenda de combustíveis é marcado por alto índice de informalidade, o que gera muitas incertezas na relação entre esses agentes. $\mathrm{O}$ segmento em que ocorrem maiores problemas ligados a adulteração e sonegação de impostos é nos canais de distribuição de postos bandeiras brancas que recebem seus combustíveis de quaisquer distribuidoras. No entanto, as grandes distribuidoras ligadas ao Sindicom também correm o risco de seus revendedores comprarem produtos de outras distribuidoras ou adulterarem seu combustível, oferecendo produtos de má qualidade, o que prejudica a imagem da companhia. Por esses motivos, neste mercado, a reputação dos membros que compõem os canais de distribuição de combustíveis é fundamental. A reputação aumenta a quantidade de informações disponíveis no instante da concretização da transação ao garantir que um conjunto de promessas sobre determinadas características do produto ou serviço transacionado torne-se consistente ao longo do tempo. O correto gerenciamento da reputação protege o valor de longo prazo da marca, que em muitos casos pode exceder o valor dos ativos tangíveis das corporações ou dos indivíduos (MACHADO, 2002).

Vale salientar que essa informalidade nos canais de distribuição de etanol faz com que a margem de lucro obtida com o produto seja menor do que a margem obtida com a gasolina, já que, por meio desta, os agentes que trabalham de maneira ilegal conseguem vender o etanol hidratado com preço reduzido; com isso, para conseguirem concorrer nesse mercado, os agentes que trabalham legalmente são obrigados a diminuir suas margens de lucro obtidas com o combustível para acompanhar o preço.

\subsection{Estrutura de governança: distribuidoras - revendedores}

As distribuidoras emergentes e as que fazem parte do Sindicom, além de distribuírem etanol para os postos revendedores com os quais estabelecem contratos de exclusividade, também distribuem seus produtos para os postos bandeiras brancas. No entanto, as grandes companhias, ao contrário das emergentes, dão menos ênfase para este mercado, já que esses revendedores competem diretamente com os seus, que, normalmente, devido a todo o investimento no empreendimento do negócio, vendem seus produtos com um valor maior do que os postos bandeiras brancas.

A forma de governança que ocorre entre os postos bandeirados e as distribuidoras é sempre contratual. Já entre os postos bandeiras brancas e as distribuidoras, a forma de governança é sempre a de mercado (spot). Essa diferença nos arranjos contratuais faz com que, no caso do posto bandeira branca, o revendedor tome todas as decisões sobre a forma com que irá promover seu estabelecimento, desenvolvendo todo o estudo de mercado por conta própria. Já os postos bandeirados são assessorados pelas distribuidoras com as quais possuem vínculo de exclusividade. Essa distribuidora desenvolve o planejamento de marketing do posto, elabora promoções, oferece treinamento para a equipe do posto, gera serviços, desenvolve todo o layout e divulgação da marca.

Existem diferentes tipos de contratos firmados entre as distribuidoras e os postos bandeirados. Os principais contratos assinados entre esses agentes podem ser observados no Quadro 2. 
Quadro 2. Tipos de contratos firmados entre as distribuidoras e postos revendedores.

\begin{tabular}{|c|c|}
\hline Tipos de contratos & Características \\
\hline $\begin{array}{l}\text { Contrato } \\
\text { de CVM }\end{array}$ & $\begin{array}{l}\text { É o Contrato de Venda Mercantil (CVM), assinado entre o posto revendedor e a } \\
\text { Companhia Distribuidora de Combustíveis. Nesse contrato, há uma promessa de compra } \\
\text { de combustíveis e outros produtos durante um período de tempo. Tal contrato normalmente } \\
\text { é associado ao de uso de imagem para veiculação de marcas. No entanto, nem todas as } \\
\text { companhias vinculam os dois contratos. Assim, esse contrato pode ser assinado por tempo } \\
\text { definido ou por volume, em que é definida a quantidade de combustíveis a ser adquirida } \\
\text { em um determinado tempo contratual. Em troca da assinatura do CVM, o revendedor } \\
\text { pode obter algum benefício da Companhia, como financiamento, valor a fundo perdido, } \\
\text { substituição de equipamentos, comodato de equipamentos e imagem. } \\
\text { - Financiamento: dinheiro cedido pela distribuidora para investimento no posto, devendo } \\
\text { ser pago em longo prazo e com acréscimo de juros e correção monetária. } \\
\text { - Valor a fundo perdido ou absorvível: dinheiro cedido pela distribuidora para } \\
\text { investimentos no posto sem a devolução para a companhia. Vale frisar que, com as } \\
\text { margens se estreitando cada vez mais pelo grande aumento da concorrência, hoje em dia } \\
\text { não há espaço para tal benefício; apesar de ainda existir, ocorre de uma maneira muito } \\
\text { restrita e condicionado a diversas exigências. } \\
\text { - Substituição de equipamento: em vez de dinheiro, as distribuidoras oferecem serviços de } \\
\text { manutenção ou troca de máquinas e equipamentos existentes no posto. } \\
\text { - Comodato de equipamentos e imagem: é a cessão de equipamentos como bombas, } \\
\text { tanques, etc., para postos novos, associado também ao uso da imagem (logo, cores, } \\
\text { marca, etc.) da distribuidora. }\end{array}$ \\
\hline $\begin{array}{l}\text { Contrato de } \\
\text { locação }\end{array}$ & $\begin{array}{l}\text { É o contrato assinado entre a Companhia Distribuidora e o posto de combustível, ou entre o } \\
\text { proprietário do imóvel e o posto. Quando a propriedade pertence à Companhia, normalmente } \\
\text { o contrato é assinado por tempo indeterminado, o que faculta às partes a rescisão contratual } \\
\text { com um simples comunicado. Se a propriedade pertence a uma pessoa particular, o contrato é } \\
\text { assinado por tempo definido, podendo ser renovado ao término do prazo, ou, na falta de uma } \\
\text { renovação amigável, pode-se obter a renovação via trâmite judicial. }\end{array}$ \\
\hline $\begin{array}{l}\text { Contrato de } \\
\text { sublocação }\end{array}$ & $\begin{array}{l}\text { Este contrato normalmente é assinado quando a propriedade pertence a uma pessoa } \\
\text { particular que aluga o imóvel para a Companhia Distribuidora, a qual transfere a locação } \\
\text { para o posto. }\end{array}$ \\
\hline $\begin{array}{l}\text { Contrato de } \\
\text { comodato }\end{array}$ & $\begin{array}{l}\text { Este contrato é assinado entre as partes, quando a Companhia Distribuidora fornece algum } \\
\text { equipamento ao posto, a título de empréstimo. Pode ser assinado também entre o posto e } \\
\text { algum fornecedor, como Coca-Cola, Brahma, Gelo, etc. Este tipo de contrato traz algumas } \\
\text { vantagens, como o fato de a manutenção do equipamento ficar a cargo do fornecedor, } \\
\text { sem onerar o posto. Um exemplo típico é a atual regulamentação do Conama, de acordo } \\
\text { com a qual as distribuidoras ficam com o ônus da troca de tanques para cumprimento das } \\
\text { exigências legais. }\end{array}$ \\
\hline
\end{tabular}

Fonte: Elaborado pelos autores com base nas entrevistas e documentos coletados.

\section{Conclusão e sugestões para trabalhos futuros}

A análise das dimensões das transações entre as distribuidoras e os postos revendedores mostra que as especificidades mais importantes de uma distribuidora de combustíveis estão ligadas às físicas, às exigências de definição do local e às de desenvolvimento da marca. As especificidades dos postos revendedores são as mesmas que as das distribuidoras, apresentando diferenças nas formas de especificidades locacionais e de ativos físicos.

Em relação às frequências das transações entre as distribuidoras e os revendedores, a comercialização do etanol entre a distribuidora e um posto bandeirado é sempre recorrente, pois se dá por meio de contratos. Já no caso da comercialização do combustível entre uma distribuidora e um posto bandeira branca, mesmo que muitos desses postos prefiram manter negociações com poucas distribuidoras de sua confiança, a frequência das transações é ocasional, pois não são firmados contratos de longo prazo entre a distribuidora e esse agente, o que lhe permite optar pela distribuidora que lhe ofereça as melhores vantagens no momento da aquisição do combustível.

No que diz respeito à incerteza, nota-se que, para a distribuidora, ela se manifesta de forma muito maior em sua relação com os postos revendedores do que na relação da distribuidora com as usinas. Pode-se analisar o fato considerando as diferentes barreiras à entrada nos dois negócios. As poucas barreiras de entrada e as facilidades para deixar de ser uma 
distribuidora ou um revendedor fizeram com que esse mercado, pós-desregulamentação, se corrompesse, o que levou ao aumento da desconfiança entre esses agentes.

$\mathrm{Na}$ transação entre distribuidoras e postos revendedores, as distribuidoras emergentes e as que fazem parte do Sindicom, além de distribuírem etanol para os postos revendedores com os quais estabelecem contratos de exclusividade, também distribuem seus produtos para os postos de bandeira branca. No entanto, as grandes companhias, ao contrário das emergentes, dão menos ênfase para este mercado, já que esses revendedores competem diretamente com os seus, que normalmente, devido a todo o investimento no empreendimento do negócio, vendem seus produtos com um valor maior do que os postos de bandeira branca.

A forma de governança que ocorre entre os postos bandeirados e as distribuidoras é sempre contratual. Já entre os postos de bandeira branca e as distribuidoras, a forma de governança é sempre via mercado (spot). Essa diferença nos arranjos contratuais faz com que, no caso do posto de bandeira branca, o revendedor tome todas as decisões sobre a forma com que irá promover seu estabelecimento, desenvolvendo todo o estudo de mercado por conta própria. Já os postos bandeirados são assessorados pelas distribuidoras com as quais possuem vínculo de exclusividade. Essa distribuidora desenvolve o planejamento de marketing do posto, elabora promoções, oferece treinamento para a equipe do posto, gera serviços, desenvolve todo o layout e a divulgação da marca.

Como sugestões para trabalhos futuros, são apontadas algumas opções de estudos. A primeira delas poderia envolver uma pesquisa utilizando o método de estudo de caso que teria como objetivo estudar empresas que verticalizaram a produção e a distribuição de etanol, identificando quais as dificuldades e os benefícios adquiridos no processo de integração vertical.

Ainda nesta direção, poderiam se comparar as diferentes estratégias utilizadas por usinas que integram verticalmente a produção e a distribuição de etanol, usinas que distribuem o produto via intermediário (exemplos: corretoras, filiais de comercialização) e usinas que distribuem o combustível diretamente (sem intermediários) para as companhias distribuidoras. Também seria interessante analisar como as distribuidoras emergentes e as ligadas ao Sindicom se organizam no mercado e as diferentes estratégias utilizadas por elas para a distribuição de etanol carburante.

Outra contribuição relevante seria a tentativa de proposição de um modelo estratégico para a construção de canais de distribuição de etanol mais eficientes. Esse trabalho estudaria as lacunas presentes nesses canais e proporia soluções para elas. Dentro desse enfoque, poder-se-ia ampliar o leque do estudo, incluindo empresas de outras regiões (fora o Estado de São Paulo), onde a produção de etanol vem se expandindo, e identificando-se como se dão essas novas relações entre as usinas, as distribuidoras e as instituições locais; outra abordagem desta proposição de estudo é o que poderia ser feito para aperfeiçoar esses novos canais de distribuição de etanol.

Por último, vale sugerir uma vertente de estudos que poderia considerar as diferentes estratégias de marketing utilizadas pelos postos bandeirados e de bandeira branca, assim como a localização e a agregação de serviços.

\section{Referências}

ANDERSON, E. The salesperson as outside agent or employee: a transaction cost analysis. Marketing Science, v. 4, n. 3, p. 234-54, 1985. http://dx.doi. org/10.1287/mksc.4.3.234

ANDERSON, J. C.; NARUS, J. A. A model of distribution firm and manufacturer firm working partnerships. Journal of Marketing, v. 54, p. 42-58, 1990. http:// dx.doi.org/10.2307/1252172

AULAKH, P. S.; GENCTURK, F. E. Contract formalization and governance of exporterimporter relationships. Journal of Management Studies, v. 45, n. 3, p. 457-479, 2008. http://dx.doi.org/10.1111/j.1467-6486.2007.00746.x

AGÊNCIA NACIONAL DO PETRÓLEO - ANP. Anuário estatístico brasileiro do petróleo, gás natural e biocombustíveis. 2008. Disponível em: <http://www. anp.gov.br/conheca/anuario_2008.asp\#secao_3>. Acesso em: jan. 2009.

AZEVEDO, P. F. Integração vertical e barganha. 220 f. Tese (Doutorado em Economia)-Faculdade de Economia, Administração e Contabilidade, Universidade de São Paulo, São Paulo, 1996.

BOYD, H. W.; WESTFALL, R. Pesquisa mercadológica: textos e casos. 7. ed. Rio de Janeiro: Fundação Getúlio Vargas, 1987. http://dx.doi.org/10.2307/1251126

DOLNIKOFF, F. Contratos de etanol carburante e a racionalidade econômica da relação entre usinas e distribuidoras de combustíveis no Brasil. $162 \mathrm{f}$. Dissertação (Mestrado em Administração) - Faculdade de Economia, Administração e Contabilidade, Universidade de São Paulo, São Paulo, 2008.

DWYER, F. R.; SCHURR, P. H; OH, S. Developing buyer-seller relationships. Journal of Marketing, n. 51, p. 11-27, 1987.

FARINA, E. M. M. Q.; AZEVEDO P. F.; SAES, M. S. M. Competitividade: mercado, estado e organizações. São Paulo: Editora Singular, 1997.

HEIDE, J. B.; JOHN, G. The role of dependence balancing in safeguarding transaction-specific assets in conventional channels. Journal of Marketing, v. 52, p. 20-35, 1988. http://dx.doi.org/10.2307/1251683

JAP, S. D.; ANDERSON, E. Safeguarding interorganizational performance and continuity under ex post opportunism. Management Science, v. 49, p. 1684-1701, 2003. http:// dx.doi.org/10.1287/mnsc.49.12.1684.25112 
KIM, S. K. Relational behaviors in marketing channel relationships: transaction cost implications. Journal of Business Research, v. 60, p. 1125-1134, 2007. http:// dx.doi.org/10.1016/j.jbusres.2007.03.006

KLEIN, S.; FRAZIER, G. L; ROTH, V. J. A transactional cost analysis model of channel integration in international markets. Journal of Marketing Research, v. 27, p. 196-208, 1990. http://dx.doi.org/10.2307/3172846

LEE, Y.; CAVUSGIL, S. T. Enhancing alliance performance: the effects of contratual-based versus relational-based governance. Journal of Business Research, v. 59, p. 896-905, 2006. http://dx.doi.org/10.1016/j. jbusres.2006.03.003

LUI, S. S.; WONG, Y.; LIU W. Asset specificity roles interfirm cooperation: reducing opportunistic behavior or increasing cooperative behavior? Journal of Business Research, v. 62, n. 11, p. 1214-1219, 2009.

MENARD, C. The economics of hybrids organizations. Journal of Institutional and Theoretical Economics, v. x, n. x, p. 345-376, 2004. Disponível em: <http:// atom.univparis1. fr/documents/Menard_JITE_2004. pdf>. Acesso em: ago. 2008.

MENARD, C. On clusters, hybrids, and other strange forms: the cesa of the French poultry Industry. Journal of Institutional and Theoretical Economics, v. 152, p. 155-183, 2001.

MACHADO, E. L. O papel da reputação na coordenação vertical da cadeia produtiva de frutas, legumes e verduras frescos. $182 \mathrm{f}$. Tese (Doutorado em Economia) Faculdade de Economia, Administração e Contabilidade, Universidade de São Paulo, São Paulo, 2002.

NEVES, M. F. Um modelo para planejamento de canais de distribuição no setor de alimentos. Tese (Doutorado em Administração)-Faculdade de Economia, Administração e Contabilidade, Universidade de São Paulo, São Paulo, 1999.

NORTH, D. C. Institutions, institutional change and economic performance. Cambridge: Cambridge University Press, 1990.

PETERSON, H. C.; WYSOCKI, A.; HARSH, S. B. Strategic choice along the vertical coordination continuum. International Food and Agribusiness Management Review, v. 4, n. 2, p. 149-166, 2001. http://dx.doi. org/10.1016/S1096-7508(01)00079-9

PIRES, A.; SCHECHTMAN, R. A ameaça do pré-sal aos biocombustíveis. 2008. Disponível em: <http://www. unica.com.br/opiniao/show.asp?msgCode $=\{$ E14D09EE1C77-4B60-8B5A-03D7CF2ACB44\}>. Acesso em: mar. 2009.
POPPO L.; ZENGER, T. Do formal contracts and relational governance function as substitutes or complements? Strategic Management Journal, v. 23, n. 8, p. 707-725, 2002. http://dx.doi.org/10.1002/smj.249

RINDFLEISCH, A.; HEIDE, J. Transaction cost analysis: past, present, and future applications. Journal of Marketing, v. 61, n. 4, p. 30-54, 1997. http://dx.doi. org/10.2307/1252085

RODRIGUES, A. P.; RODRIGUES, L. O etanol e os desafios do mercado interno. 2008. Disponível em: <http://www.unica.com.br/opiniao/show. asp? $\mathrm{msgCode}=\{653 \mathrm{FC} 86 \mathrm{C}-\mathrm{D} 21 \mathrm{E}-455 \mathrm{~A}-\mathrm{BFFF}-$ 5299131A1680\}>. Acesso em: nov. 2008.

SELLTIZ, C. et al. Método de pesquisa nas relações sociais. São Paulo: EPU, 1974.

SINDICATO NACIONAL DAS EMPRESAS DISTRIBUIDORAS DE COMBUSTÍVEIS E DE LUBRIFICANTES - SINDICOM. Disponível em: $<$ www.simdicom.com.br>. Acesso em: jan. 2009.

TRIVIÑOS, A. N. S. Introdução à pesquisa em ciências sociais: a pesquisa qualitativa em educação. São Paulo: Atlas, 1992.

UNIÃO DA AGROINDÚSTRIA CANAVIEIRA DE SÃO PAULO - UNICA. Dados e cotações: estatísticas. 2008. Disponível em: <http://www.unica.com.br/dadosCotacao/ estatistica/>. Acesso em: jan. 2009.

VIAN, C. E. F. Inércia e mudanças institucionais: estratégias competitivas do complexo agroindustrial canavieiro no centro-sul do Brasil. Tese (Doutorado em Economia)-Instituto de Economia, Universidade Estadual de Campinas, Campinas, 2002.

WILLIAMSON, O. Markets and hierarchies. New York: Free Press, 1975.

WILLIAMSON, O. The economic institutions of capitalism: firms, markets, relational contracting. New York: The Free Press, 1985.

WILLIAMSON, O. Mechanism of governance. New York: Oxford University Press, 1996.

YIN, R. K. Estudo de caso: planejamento e métodos. 3. ed. Trad. Daniel Grassi. Porto Alegre: Bookman, 2005.

ZYLBERSZTAJN, D. Estruturas de governança e coordenação do agribusiness: uma aplicação da Nova Economia das Instituições. Tese (Livre Docência)Faculdade de Economia, Administração e Contabilidade, Universidade de São Paulo, São Paulo, 1995.

ZYLBERSZTAJN, D. Conceitos gerais, evolução e apresentação do sistema agroindustrial. In: ZYLBERSZTAJN, D.; NEVES, F. N. Gestão dos negócios agroalimentares. São Paulo: Pioneira, 2000. p. 1-21. 